\title{
Histopathological Study of Prostatic Carcinoma in Relation to Gleason Grade, Serum PSA and Ki67 Immunomarker
}

\author{
Kanna Sandhyarani Mahadev*, B R Vani and Srinivas Murthy.V \\ Department of Pathology,Employees State Insurance Corporation \& Post Graduate Institute of Medical Sciences \& \\ Research (ESIC\&PGIMSR), ESI Model Hospital,Bangalore- India
}

\begin{abstract}
Introduction: Carcinoma of prostate (CaP) is the second most common cancer in men.Gleason's score (GS) and pretreatment serum prostate specific antigen (sPSA) levels are important parameters in diagnosis and therapeutic decision making. Recent studies have found that GS tends to undergrade tumors and sPSA levels are not cancer specific. The present study highlights correlation between immunomarker Ki67, GS and sPSA which provides a objective method of grading tumors and helps in better prognostication of patients.
\end{abstract}

Objectives: 1. To study histopathology of prostate carcinoma and its variants and assign them Gleason score as per the Gleason grading system. 2. To study Ki-67 immunoexpression in prostate carcinoma. 3. To correlate Ki-67 expression, Gleason scoring and serum prostate specific antigen levels in prostate carcinoma

Methods: A retro-prospective study was done on 100 specimens of prostate carcinoma from the year 2010-2015 in Department of Pathology of ESIC Medical College and PGIMSR, Rajajinagar, Bangalore for a period of 18 months(November2013-April2015).Each case was assigned Gleason score and subjected to immunohistochemistry for Ki67 expression. Results of Ki67 expression was correlated with Gleason score and PSA levels.

Results: Out of the 100 cases studied, all case were of acinar/usual adenocarcinoma-WHO type. 40 cases were moderately differentiated, 39 cases were high grade tumors and 21 cases were intermediate grade tumors. Serum PSA levels increased with increase in GS. Ki67 labelling index showed a proportionate increase with increase in GS and serum PSA which was statistically significant.

Conclusion: Ki67 is a new emerging biomarker which is significantly associated with tumor grade and pretreatment PSA levels and can be used as an additive parameter or a substitution to known prognostic variables to aid in therapeutic interventions.

Keywords: Adenocarcinoma, Gleason Score, Immunolabelling Index, Ki67, Prostate, Serum PSA.

\section{Introduction}

Prostate cancer is the second most common cancer in men and is the fifth leading cause of death in them according to fact sheets of GLOBOCAN 2012.[1] Similar scenario exists in India with prostate cancer being on the rise and now the second leading cancer among males. ${ }^{[2]}$ Rise in the incidence is partly attributed to screening with PSA levels. ${ }^{[1]}$ Prostatic biopsies are increasingly being used to diagnose prostatic carcinomas. Once diagnosis of adenocarcinoma is made, it is graded using Gleason scoring system. Grading is of importance in prostatic cancer, because grade and stage are the best prognostic predictors. ${ }^{[3]}$ Till date, Gleason grade is used as an important prognostic marker. ${ }^{[3]} \mathrm{But}$ recent studies using various biomarkers have proved that many prostatic carcinomas have been over graded or under graded using Gleason scoring system.$^{[4]}$ This may be attributed to its subjective nature and it aroused the need to search for novel markers which are more objective and hence can correctly predict the behavior of $\mathrm{CaPs}^{\left[{ }^{[4]}\right.} \mathrm{Ki} 67$ is one of the frequently used novel marker used in almost all malignancies to predict the proliferative capacity. Ki67 is an antigen that corresponds to a nuclear non-histone protein expressed by cells in the proliferative phases G1, G2, M, and S. ${ }^{[5]}$ Immunostaining with Ki67not only provides objective method of grading CaPs, but is more reproducible than Gleason grading system. It is also more predictable than PSA. Hence this study was conducted to study expression of $\mathrm{Ki} 67$ in $\mathrm{CaPs}$ and its correlation with Gleason score(GS) and PSA to provide more accurate method of predicting the prognosis in cases of carcinoma of prostate

\section{Materials \& Methods}

Samples-This study was conducted over a period of 18 months (Nov 2013 to April 2015).A total of 100 patients with diagnosis of prostatic carcinoma on biopsies and transrectal urethral resection specimens(TURP) were included in the study. All tumor samples were routinely processed. The patient's medical records were reviewed to 
obtain patient's clinico-pathological parameters, including age at diagnosis, pretreatment sPSA values, digital rectal examination findings, type of procedure, ultrasonography and CT scan findings. Histological diagnosis was given according to WHO classification. All cases were assigned Gleason score by Gleason scoring system. There are five Gleason patterns and Gleason score ranges from 2 to 10 . GS were combined into four groups -well differentiated (score 2-4), intermediate grade(score5\&6), moderately differentiated (score 7), high grade (score 8\&above). Presence or absence of perineural invasion (PNI) and prostatic intraepithelial neoplasia (PIN) was also noted.

Immunohistochemistry- Immunohistochemistry for Ki67 was done on all the cases. The percentage of cells positive for Ki-67 was scored according to the number of labeled cells observed. Each slide was evaluated at 4X10 magnification in order to find areas with maximum positive cells. Then these areas were examined at $400 \mathrm{X}$ magnification and the percentage of positive cells to total cells was calculated. At least 500 cells were counted and only the cells that were definitely positive for the desired marker were considered. Criteria for Ki67 positivity were strong and complete brown yellowish nuclear coloration. Nuclei of stromal cells and lymphocytes which took up the stain were not counted. Basal cells of adjacent non neoplastic prostatic glands and colonic epithelium were taken as positive internal control. For negative control, the step involving the primary antibody was omitted. Grading criteria used for assessing Ki67 immunolabelling index as shown in table1.

Statistical Analysis-The results were analyzed using SPSS software v 9.0. Descriptive statistics was done for age distribution, distribution of clinical features among study cases, ultrasonography findings, digital rectal examination finding, presence of bony metastasis, types of specimen,presence of perineural invasion and PIN, Ki-67 expression, PSA levels and Gleason's grading. Spearman's correlation test was used to evaluate correlation between Gleason's grading and Ki-67 expression;Gleason's grading and PSA level; and between $\mathrm{Ki}-67$ and PSA level. A $p$ value of $<0.05$ was considered as statistically significant. Parametric test ANOVA was used to analyze Ki-67 immunolabelling index and PSA level between different Gleason's grade.

\section{Results}

All 100 cases were studied histopathologically and evaluated for Ki67 expression in relation to Gleason score and serum PSA levels. The mean age of patient was 66.6years. The most common complaint was urinary retention.Digital rectal examination was abnormal in $40 \%$ of cases.55\% patients had grade II prostatomegaly on ultrasonography. Bony metastasis was diagnosed in 33\% of cases with remaining $67 \%$ having carcinoma confined to prostate. The mean PSA was $128.00 \pm 63.97 \mathrm{ng} / \mathrm{ml}$. Only $12 \%$ of patients had a PSA value $>201$ with maximum value of $239 \mathrm{ng} / \mathrm{ml}$. The minimum value of PSA was $1.46 \mathrm{ng} / \mathrm{ml}$. Majority of patients had values between 51 and 200ng/ $\mathrm{ml}$. Sixty five percent of specimens were biopsies and remaining $35 \%$ of specimens were TURP.All cases were usual prostatic adenocarcinoma (WHO classification). Perineural invasion was seen in $38 \%$ of cases and $52 \%$ of the cases showed adjacent prostatic intraepithelial lesion. All cases were assigned a Gleason score and grouped into four categories as in methodology.Maximum cases were of moderately differentiated type $(40 \%)$,high grade tumors were seen in $39 \%$ of cases with remaining being intermediate grade $(21 \%)$. One case had tertiary component with grade 2 in a TURP specimen which constituted $<5 \%$. According to WHO criteria, this was insignificant hence was not considered. No high grade tertiary patterns were observed. Maximum number of cases $(40 \%)$ were in age group of 61-70 and these were chiefly moderately differentiated. With increasing age there was increase in the Gleason score. The distribution of PSA levels(table2) in different categories of Gleason score groups showed that majority of moderately differentiated tumors had PSA levels between 101-150.99ng/ml. A statistically significant correlation was observed between increasing levels of PSA level and higher Gleason's score (Spearman correlation test) with $\mathrm{p}$ value of 0.0001 and correlation coefficient of +0.715 . There was a statistically significant ( $\mathrm{P}$ value $<0.05$ ) difference in mean PSA levels between different Gleason's grade with mean $\pm \mathrm{SD}$ value of $62.30 \pm 35.99, \quad 118.60 \pm 47.89$ and $173.025 \pm 55.38$ in intermediate grade, moderately differentiated and high grade tumors respectively. Thus, with increasing grade the mean sPSA levels also increased. The 100 cases of $\mathrm{CaP}$ were immunohistochemically stained with Ki-67 antibody. Majority of the cases (85\%) of cases had moderate Ki-67 expression with mean labeling index of $47.9 \pm 16.82 \%$. The proportion of immunoexpression of Ki-67 in tumor cells increased as the grade of tumor increased.Only high grade tumors $(7.69 \%)$ showed intense staining. A statistically significant correlation was observed between Ki-67 expression and Gleason's grade (Spearman correlation test) with $p$ value of 0.0001 and correlation coefficient of +0.513 . There was significant increase in Ki-67 expression as the Gleason's score increased with mean $\pm \mathrm{SD}$ of 32.95 $\pm 14.74,48.57 \pm 13.34$ and $55.29 \pm 16.14$ in intermediate grade, moderately differentiated and high grade tumors respectively $(\mathrm{P}<0.05)$ (table 3$)$.Ki67 expression in relation to various ranges of PSA showed that with increasing 
levels of sPSA the percentage of cases showed a significant increase in Ki-67 expression with a $\mathrm{P}$ value of 0.0001 and Spearman's correlation coefficient of +0.366 . More than $75 \%$ immunolabelling of Ki67 was noted only in the patients with serum PSA of 151 and above. (table 4)
Comparing all the three important parameters of the study: Gleasons score, serum PSA, Ki67 immunolabelling index, we found that with increasing Gleason score and increasing serum PSA levels, the proportion of cells expressing Ki67 also increased (as shown in table 5)

Table 1: Grading criteria used for assessing Ki67 immunolabelling index.

\begin{tabular}{|c|c|}
\hline Percentage of cells & Grading \\
\hline$<2 \%$ & Negative \\
\hline $2-25 \%$ of labeled cells & Weak $(+)$ \\
\hline $25-75 \%$ & Moderate $(++)$ \\
\hline$>75 \%$ & Intense $(+++)$ \\
\hline
\end{tabular}

Table 2: Distribution of cases based on PSA levels and Gleason's score.

\begin{tabular}{|c|c|c|c|c|c|c|}
\hline & \multicolumn{7}{|c|}{ PSA (ng/ml) } \\
\hline Gleason's grade & $\mathbf{1 . 0 - 5 0 . 9 9}$ & $\mathbf{5 1 - 1 0 0 . 9 9}$ & $\mathbf{1 0 1 - 1 5 0 . 9 9}$ & $\mathbf{1 5 1 - 2 0 0 . 9 9}$ & $\mathbf{7 2 0 1}$ & $\mathbf{( \% )}$ \\
\hline Well differentiated & 0 & 0 & 0 & 0 & 0 \\
\hline Intermediate grade & 10 & 9 & 1 & 1 & 0 & 21 \\
\hline Moderately differentiated & 2 & 14 & 17 & 4 & 3 & 40 \\
\hline High grade & 0 & 5 & 7 & 18 & 9 & 39 \\
\hline Total & $\mathbf{1 2}$ & $\mathbf{2 8}$ & $\mathbf{2 5}$ & $\mathbf{2 3}$ & $\mathbf{1 2}$ & $\mathbf{1 0 0}$ \\
\hline
\end{tabular}

Table 3: Distribution of cases based on Ki-67 expression and Gleason's score.

\begin{tabular}{|c|c|c|c|}
\hline & \multicolumn{3}{|c|}{ Ki-67 immunolabelling index } \\
\hline Gleason grade & $\mathbf{2 - 2 5 \%}$ & $\mathbf{2 5 - 7 5 \%}$ & $\mathbf{7 7 5 \%}$ \\
\hline Well differentiated & 0 & 0 & 0 \\
\hline Intermediate grade & $6(28.6 \%)$ & $15(71.4 \%)$ & 0 \\
\hline Moderately differentiated & $2(5 \%)$ & $38(95 \%)$ & $3(7.69 \%)$ \\
\hline High grade & $4(10.26 \%)$ & $32(82.05 \%)$ & $\mathbf{0 3}$ \\
\hline Total & $\mathbf{1 2}$ & $\mathbf{8 5}$ & 0 \\
\hline
\end{tabular}

Table 4. Distribution of cases based on Ki 67 expression and PSA level.

\begin{tabular}{|c|c|c|c|c|}
\hline \multirow{2}{*}{ PSA(ng/ml) } & \multicolumn{3}{|c|}{ Ki67 } & Percentage \\
\cline { 2 - 5 } & $\mathbf{2 - 2 5 \%}$ & $\mathbf{2 5 - 7 5 \%}$ & 0 & 12 \\
\hline $1.0-50.99$ & 4 & 8 & 0 & 28 \\
\hline $51-100.99$ & 2 & 26 & 0 & 25 \\
\hline $101-150.99$ & 5 & 20 & 1 & 23 \\
\hline $151-200.99$ & 1 & 21 & 2 & 12 \\
\hline$>201$ & 12 & 10 & $\mathbf{0 3}$ & 100 \\
\hline
\end{tabular}

Table 5: Ki-67 immunolabelling index and PSA levels in different Gleason's score.

\begin{tabular}{|c|c|c|c|}
\hline Gleason's grade & No of patients & $\begin{array}{c}\text { Ki } 67 \text { immunolabelling index } \\
\text { (mean } \pm \text { SD) }\end{array}$ & PSA level (mean \pm SD) \\
\hline Intermediate grade (5\&6) & 21 & $32.95 \pm 14.74$ & $62.30 \pm 35.99$ \\
\hline Moderately differentiated (7) & 40 & $48.57 \pm 13.35$ & $118.60 \pm 47.89$ \\
\hline High grade (8 \& above) & 39 & $55.29 \pm 16.14$ & $173.02 \pm 55.38$ \\
\hline
\end{tabular}


Table 6 : Ki67 expression with reference to Gleason score in prostate carcinoma.

\begin{tabular}{|c|c|l|}
\hline Study & No.of cases & Conclusion \\
\hline Madani et $\mathrm{al}^{7}$ & 49 & Statistically significant correlation between the Ki-67 labelling with GS. \\
\hline Aaltomaa et $\mathrm{al}^{28}$ & 211 & Positive correlation between Ki67, pT and differentiation of tumours \\
\hline M.Tsuji et al ${ }^{29}$ & 79 & $\begin{array}{l}\text { Ki67 labelling index increased with increasing grade. Mean Ki67 LI for Gleason score } \\
2-6 \text { was } 11.6 \% \text { and patients with score 8-10 had LI of 24.7. }\end{array}$ \\
\hline Mesko et al ${ }^{30}$ & 77 & $\begin{array}{l}\text { Ki67 labelling index was significantly different for Gleason scores of } 6,7, \text { and } \geq 8, \text { with } \\
\text { mean Ki-67 of } 5.0 \% \pm 3.8 \%, 7.7 \% \pm 7.0 \%, \text { and } 12.0 \% \pm 12.4 \%(P=0.01) \text { respectively }\end{array}$ \\
\hline Verma et al ${ }^{31}$ & 60 & $\begin{array}{l}\text { Statistically significant correlation between } \\
\text { Ki-67 positivity and increased Gleason's grade (P=0.002) }\end{array}$ \\
\hline Munoz E et al ${ }^{26}$ & 35 & $\begin{array}{l}\text { No statistically significant differences between the immunolabeling for Ki-67 and } \\
\text { Gleason's score. }\end{array}$ \\
\hline Present study & 100 & With increasing grade the Ki67 labelling index increased. \\
\hline
\end{tabular}

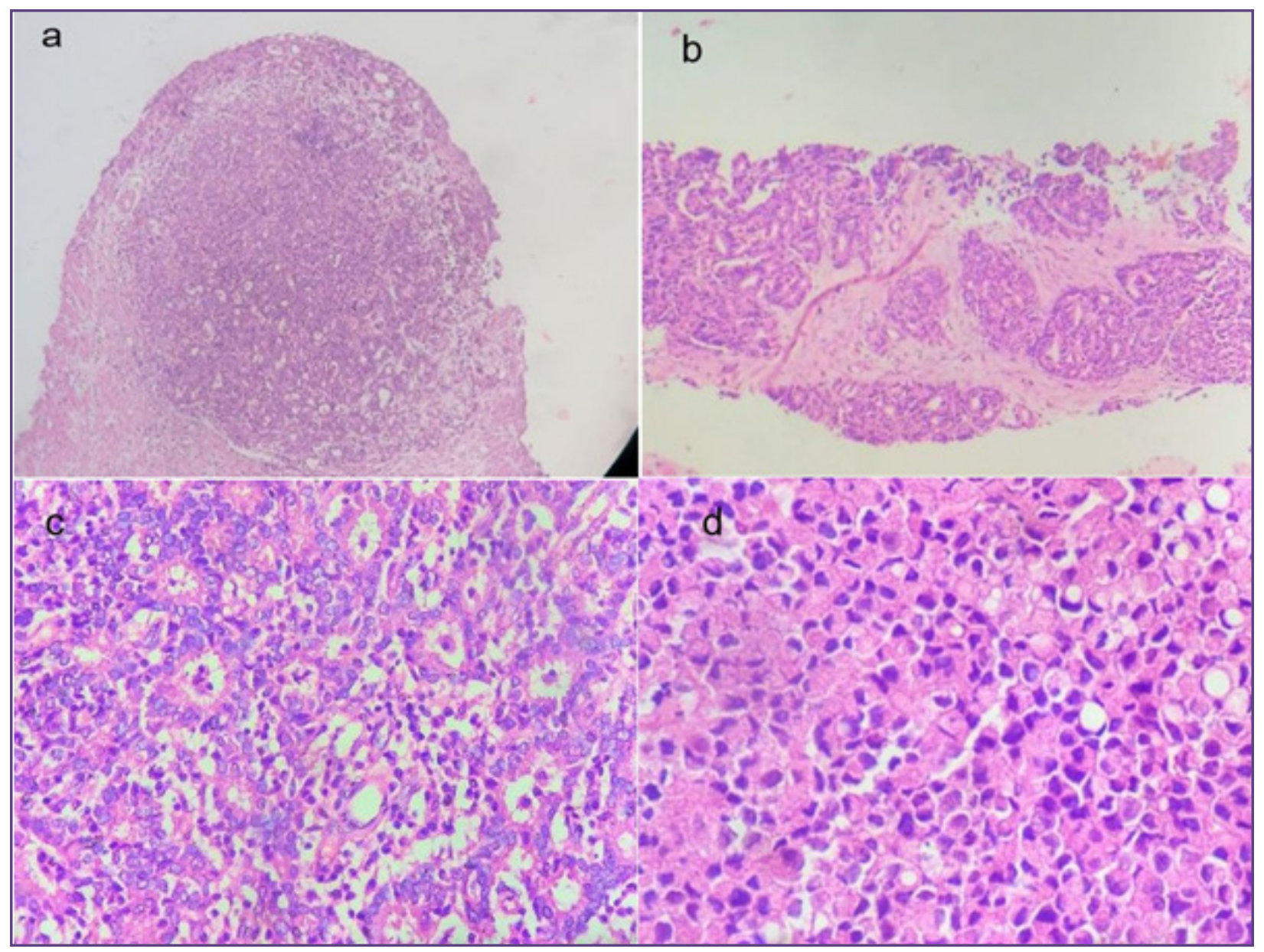

Fig. 1: Different Gleason patterns-a: Gleason pattern 2(4X),b: Gleason pattern 3(4X),c- Gleason pattern(40X) 4, d- Gleason pattern 5(40X); ( Hematoxylin \& Eosin). 


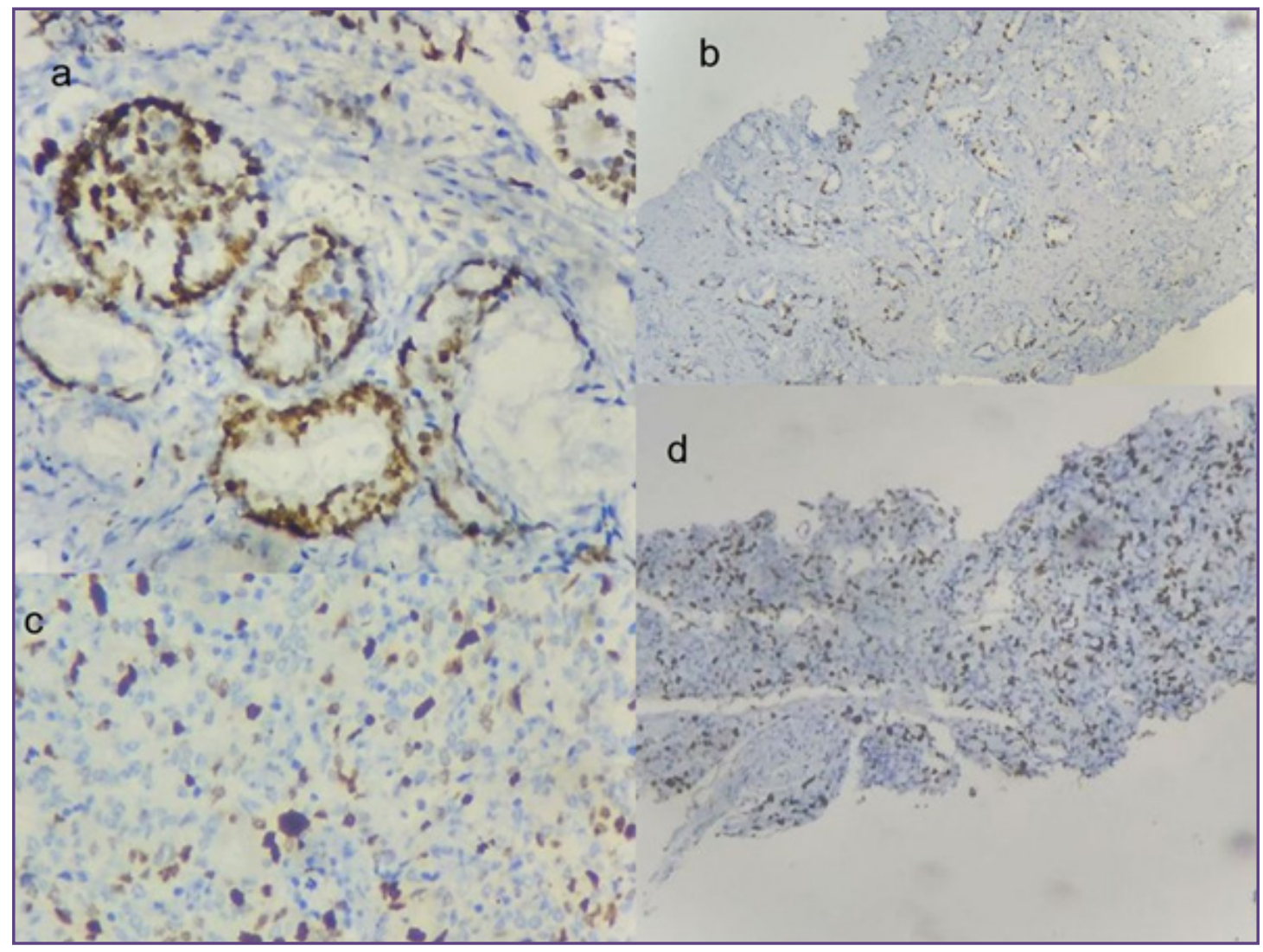

Fig. 2: Different grades of Ki67: a,b- 25-50\%(40X,4X) , c- 50-75\%(40X), d- >75\%(4X)( Anti-Ki67 immunostaining).

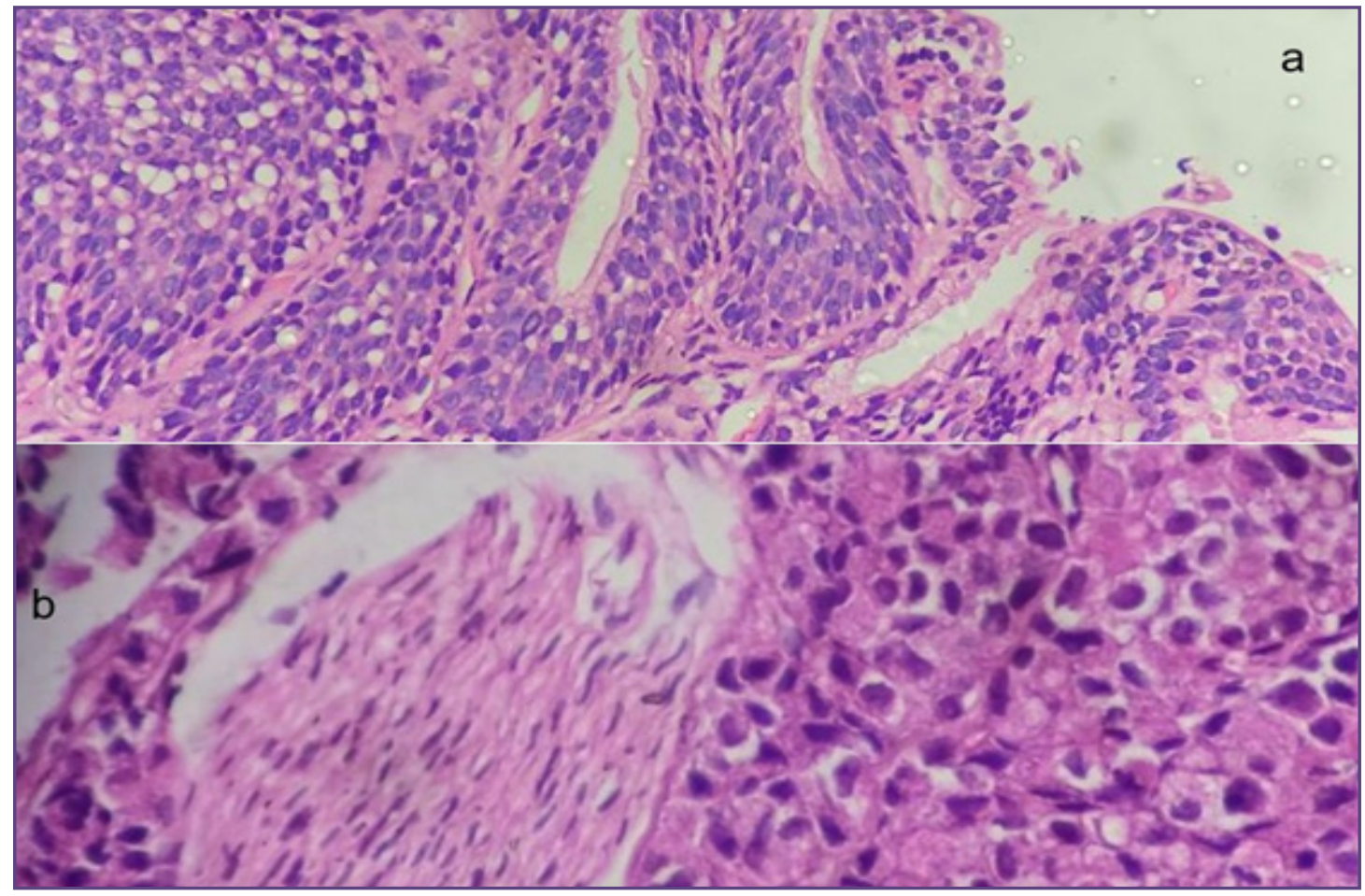

Fig. 3: a- Prostatic intraepithelial neoplasia , b- Perineural invasion(40X, Haematoxylin\&eosin staining). 


\section{Discussion}

The demographic profile,clinical details, bone scan results of the patient population of our study matches numerous studies conducted in relation to prostatic carcinoma.[6-17] The mean pretreatment PSA levels in various studies was different with a wide range.A study by Alpeshpuri et al [18] found a low value, of about $20.33 \mathrm{ng} / \mathrm{ml}$ while a study by Albasri et al [19] reported serum PSA as high as $363.4 \mathrm{ng} / \mathrm{ml}$ in CaP.In our study mean PSA level in prostate carcinoma was $128 \mathrm{ng} / \mathrm{ml}$. We had one case below the cutoffsPSA value. The different age groups, different number of cases in each study and composition of tumors of different grades in each study may account for this variability.Presence of perineural invasion is the category III prognostic variable and is associated with increased incidence of extra-prostatic extension and aggressive phenotypes.[20]Datavaries across studies with a maximum percentage of about $90 \%$ and minimum of $16 \%$.[21-23]In present study,38\% of $\mathrm{CaPs}$ showed perineural invasion.Studies having more number of well differentiated tumors have low percentages of evidence of PNI while studies with more number of high grade tumors have higher percentages of evidence of PNI. We had 39 cases of high grade tumors, so $38 \%$ of cases showing PNI was attributable to this reason. Histologic transition of high grade PIN to prostate carcinoma has been described.Various studies report high percentages of prostatic carcinomas with PIN. Bostwick DG et al [24] found that all cases in his study had adjacent areas of PIN. McNeal et al[25] found that $82 \%$ of CaPs were associated with adjacent PIN areas.In present study the percentage of CaPs showing adjacent PIN was $52 \%$.

Gleason scoring system is the most important and time proven prognostic factor in $\mathrm{CaP}$,hence studies on emerging biomarkers are conducted in correlation to Gleason score.Several methods for grouping of Gleason scores in prognostic categories have been proposed. Gleason scores 2 to 4 behave similarly and can be grouped. Gleason scores 8 to10 are usually grouped together as they represent poorly differentiated tumors. Gleasonscore 7 is a distinct entity with prognosis intermediate between that of Gleason scores $5-6$ and 8 to 10 , respectively.Hence we grouped the patients into four groups as in methodology.[20]The various studies on Ki67 expression use different grouping of Gleason scores.[26-35]The studies mentioned in the table used same system as followed in present study and the comparative data is presented in table 6.Our study patient cohort is similar to study by Fisher G with more number of moderately differentiated tumors.[27]Various studies(table 6) report different ranges of Ki67 expression in $\mathrm{CaPs}$ in their literature. Different studies have used different grading system for assessing Ki67 labelling index as described in literature.[26,27] We used grading system given by Madani $\mathrm{SH}$ et al.[7] In our study, results were comparable to Munoz E et al,with maximum cases $(85 \%)$ with Ki67 immunolabelling index in the range of $25-75 \%$. [26] Lack of internationally accepted criteria for grading Ki67 accounts for differing data among various studies. $[7,26,27]$ Variation may also be due to different number of cases with different Gleason score constituting the cases in each study. One more reason for reporting of less percentage of Ki67 labelling index might be its heterogeneity profile. Pretreatment sPSA levels is a prognostic marker and stratifies patients into differing prognostic categories. Significant association is known with increased tumor volume, GS and poor prognosis.[20] Our study results were in concordance with other studies which found a statistically significant assosciation between higher Gleason score and increased sPSA levels.[36-38]Studies across globe also showed that there is statistically significant correlation between Gleason score and proportion of cells expressing Ki67 except in one study by Munoz E et al who concluded that they didn't find significant relation between Ki67 and Gleason score which may be due to smaller sample size.[26] Our study which included 100 cases of $\mathrm{CaP}$ is in concordance with other studies.[7,27-34]A study by Rugwizangoga B et al concluded that GS and Ki67 in combination offers better prognostic information than either alone.[32] They confirmed the association between survival and Ki67 index.This implies that high grade tumors have increased proliferative potential by virtue of which they show high proliferating index and hence poor prognosis.In relation to sPSA levels and Ki67, limited data from different studies conclude that there is no statistically significant correlation between serum PSA levels and Ki67 labeling index. [32-35] Only one study by Luczynska E et al had similar findings as our study. [35] High grade tumors or tumors with poor differentiation are known to be associated with decreased serum PSA levels. These become outliers and predominance of such cases in a study may affect the correlation between these two variables. We had a sample size of 100 and there were 39 cases of high grade tumor with less outliers .Due to large sample size and more number of high grade tumors the effect of these have got nullified and hence we got the above results.

\section{Conclusion}

Acinar adenocarcinoma/Usual adenocarcinoma is the most common type of prostatic carcinoma. Therapy and prognosis is defined by the prevailing histological grade currently determined by Gleason scoring system based on primary and secondary patterns in the tumor and also pretreatment PSA levels. Ki67, a proliferative marker is expressed by tumor cells of prostatic adenocarcinoma in 
varying proportions and increases with higher grade of tumor and with increase in serum PSA levels. A newer anciliary index in the form of Ki67 labelling index would be of help in better categorization of these tumors. Hence,

Ki67 immunolabelling index can be used in conjunction with or as a substitute to Gleason scoring system for proper risk stratification to aid in therapeutic intervention and proper prognostication of prostatic carcinomas.

\section{List of Abbreviations}

$\mathrm{BPH}$ - Benign prostatic hyperplasia

$\mathrm{CaP}$ - Prostatic carcinoma

DRE - Digital rectal examination

GS - Gleason's score

HGPIN - High grade intraepithelial neoplasia

LGPIN - Low grade prostatic intraepithelial neoplasia.

$\mathrm{H}$ and $\mathrm{E}$ - Hematoxylin and Eosin

IHC - Immunohistochemistry

Ki67 LI- Ki67 labelling index

PIN- Prostate intraepithelial lesion

PNI- Perineural invasion.

PSA- Prostate specific antigen

PSAD - PSA density

SD- Standard deviation

TURP- Transurethral resection of prostate.

NBF - Neutral Buffered Formalin

TNM - Tumor, Nodes, Metastasis

USG- Ultrasonography.

VACURG-Veterans Administration Cooperative Urological Research Group

WHO - World Health Organization

\section{References}

1. Ferlay J, Soerjomataram I, Dikshit R, et al. Cancer incidence and mortality worldwide: sources, methods and major patterns in GLOBOCAN 2012. Int J Cancer 2015;136:E359-E386.

2. Jain S, Saxena S, Kumar A. Epidemiology of prostate cancer in India. Meta Gene. 2014; 2: 596-605.

3. Ebstein JI. The lower urinary tract and male genital system. In: Kumar V, Abbas AK, Fausto N, Aster JC, editors, Pathologic Basis of Disease. 8th ed. Philadelphia: Elsevier 2010; 976-80.
4. Epstein JI, Netto GN. Biopsy Interpretation of the Prostate. 2nd edn. Lippincott, Williams \& Wilkins: Philadelphia, PA, 2008.

5. Rosai J. Male Reproductive system. Rosai and Ackerman's Surgical Pathology. 10th ed. New Delhi: Reed Elsevier India Private Limited; 2011:1287-1311.

6. Fisher $\mathrm{G}$, Yang ZH, Kudahetti S, Moller H, Scardino $\mathrm{P}$, Cuzick J et al. Prognostic value of Ki-67 for prostate cancer death in a conservatively managed cohort. Br J Cancer .2013; 108: 271-277.

7. Madani SH, Ameli S, Khazaei S, Kanani M, Izadi B. Frequency of Ki67(MIB-1) and p53 expression among patients with prostate cancer. Indian J of Pathol Microbiol .2011;54:688-91.

8. Verma R, Gupta V, Singh J et al. Significance of p53 and Ki-67 expression in prostate cancer. Urology Annals.2015; 7(4): 488

9. Diaconescu D, Toma S. Prognostic significance of Mib-1 (Ki-67) expression in prostate cancer and matched lymph node metastases. Bulletin of the Transilvania University of Brasov, Series VI: Medical Sciences.2012; 5(2):65-68.

10. Hamilton W, Sharp DJ, Peters TJ, Round AP. Clinical features of prostate cancer before diagnosis: a populationbased case-control study. Br J Gen Pract .2006;56:756-762.

11. Mulholland SG, Stefanelli JL. Genitourinary cancer in the elderly. Am J Kidney Dis. 1990;16(4):324-8.

12. Scott RJr, Mutchnik DL, Laskowski TZ, Schmalhorst WR .Carcinoma of the prostate in elderly men: incidence, growth characteristics and clinical significance. J Urol.1969;101: 602-7.

13. Ojewola RW, Jeje EA, Tijani KH, Ogunjimi MA, Anunobi CC. Clinico-pathological Correlation of Digital Rectal Examination Findings Amongst Nigerian Men with Prostatic Diseases: A Prospective Study of 236 Cases. Niger J Surg. 2013;19:26-31.

14. Haid M, Rabin D, King KM, Feistein CM, Janson KL, Levine SR, et al. Digital rectal examination, serum prostate specific antigen, and prostatic ultrasound: How effective is this diagnostic triad?. J Sur Onc.1994;56:32-38.

15. Babaian RJ, Mettlin C, Kane R, Murphy GP, Lee F, Drago $J R$,et al. The relationship of prostate-specific antigen to digital rectal examination and transrectal ultrasonography: Findings of the American cancer society national prostate cancer detection project. Cancer.1992;69(5):1195-1200.

16. Bubendorf L, Schopfer A, Wagner U, Sauter G, Moch $\mathrm{H}$, Willi N,et al. Metastatic patterns of prostate cancer: an autopsy study of 1,589 patients. Hum Pathol.2000; 31:578-83.

17. Ho CC, Seong PK, Zainuddin ZM, Abdul Manaf MR, Parameswaran M, Razack AH: Retrospective study of predictors of bone metastasis in prostate cancer cases. Asian Pac J Cancer Prev.2013;14:3289-92. 
18. Goswami AP, Rupala G, Nutanbala, Goswami N. Serum PSA level in Prostatic lesions with Histopathological correlation in Gujarat. NJIRM .2011; 2(4): 33-8.

19. Albasri A, El-Siddig A, Hussainy A, Mahrous M, Alhosaini AA, Alhujaily A. Histopathologic characterization of prostate diseases in Madinah, Saudi Arabia. Asian Pac J Cancer Prev .2014;15:4175-9.

20. Eble JN, Sauter G, Epstein JI, Sesterhenn IA,editors. Pathology and Genetics of Urinary System and Male Genital Organs. World Health Organization of Tumors. Lyon:IARC Press;2004;7

21. Merrilees AD, Bethwaite PB, Russell GL, et al. Parameters of perineural invasion in radical prostatectomy specimens lack prognostic significance. Mod Pathol. 2008;21:1095-1100.

22. Nelson CP, Dunn RL, Wei JT, Rubin MA, Montie JE, Sanda MG. Contemporary preoperative parameters predict cancerfree survival after radical prostatectomy: A tool to facilitate treatment decisions. Sem Urol Oncol. 2003;21:213-18.

23. Quinn DI, Henshall SM, Brenner PC, et al. Prognostic significance of preoperative factors in localized prostate carcinoma treated with radical prostatectomy. Cancer. 2003;97:1884-93.

24. Bostwick DG, Brawer MK. Prostatic intra-epithelial neoplasia and early invasion in prostate cancer. Cancer. 1987; 15: 788-94.

25. McNeal JE, Bostwick DG. Intraductal dysplasia: A premalignant lesion of the prostate. Hum Pathol.1986; 17:64-71

26. Muñoz E, Gómez F, Paz JI, Casado I, Silva JM, Corcuera MT. Ki-67 immunolabeling in pre-malignant lesions and carcinoma of the prostate. Histological correlation and prognostic evaluation. Eur J Histochem .2003;47(2):123-8.

27. Fisher G, Yang ZH, Kudahetti S, Møller H, Scardino P, Cuzick J, et al. Prognostic value of Ki-67 for prostate cancer death in a conservatively managed cohort. Br J Cancer.2013;108(2):271-277.

28. Aaltomaa S, Karja V, Lipponen P, et al. Expression of Ki67 , cyclin D1 and apoptosis markers correlated with survival in prostate cancer patients treated by radical prostatectomy. Anticancer Res.2006;26:4873-8.

29. Tsuji M, Murakami Y, Kanayama H, Sano T, Kagawa S. Immunohistochemical analysis of Ki-67 antigen and Bcl-2 protein expression in prostate cancer: effect of neoadjuvant hormonal therapy. Br J Urol.1998;81:116-121.

30. Mesko S, Kupelian P, Demanes DJ, Huang J, Wang PC, Kamrava M. Quantifying the ki-67 heterogeneity profile in prostate cancer. Prostate Cancer.2013:1-5.

31. Verma R, Gupta V, Singh J, Verma M, Gupta G, Gupta S, et al. Significance of p53 and ki-67 expression in prostate cancer. Uroy Ann.2015; 7(4): 488-493.

32. Rugwizangoga B, Vuhahula E, Kitinya J. A Combination Of Ki67 Expression And Gleason Score For Prostatic Adenocarcinoma Offers Better Prognostic Information Than Either Alone. The Internet Journal of Urology. 2014;12(1).1-9.

33. Luczynska E, Gasinska A, Wilk W. Expression of Ki-67 (MIB-1) and GLUT-1 proteins in non-advanced prostatic cancer. Pol J Pathol.2012; 63: 272-277.

34. Cowen D, Troncoso P, Khoo VS, Zagars GK, von Eschenbach AC,Meistrich ML,et al. Ki-67 staining is an independent correlate of biochemical failure in prostate cancer treated with radiotherapy. Clin Cancer Res. 2002 ;8(5):1148-54.

35. Sulik M, Maruszak K, Puchalska J, Misiukiewicz-Poć M. Expression of $\mathrm{Ki}-67$ as a proliferation marker in prostate cancer. Polish Annals of Medicine.2011;18(1):12-19.

36. Zivkovic S. Correlation between prostate-specific antigen and histopathological difference of prostate carcinoma. Arch Oncol .2004; 12(3):148-51.

37. Gurumurthy D, Maggad R, Patel S. Prostate Carcinoma: Correlation of Histopathology with Serum Prostate Specific Antigen. International Journal of Science, Technology and Society. Special Issue: Latest Different Concepts of Gynaecology. 2015;4:p1-5. doi: 10.11648/j. sjcm.s.2015040401.11

38. Anderson-Jackson L, McGrowder DA, Alexander-Lindo R. Prostate specific antigen and gleason score in men with prostate cancer at a private diagnostic radiology centre in Western Jamaica. Asian Pac J Cancer Prev.2012; 13:1453-6.

*Corresponding author:

Dr. KannaSandhyarani Mahadev, Add-Central Lab, Department of Pathology, Basement floor, P.K Das Hospital, Vaniamkulam.Kerala-679522

Phone: +91 9620115677

Email: careattouchsam@gmail.com

Financial or other Competing Interests: None. 